\title{
Effectiveness of alternative therapies for the management of lumbar disc disease: a descriptive research
}

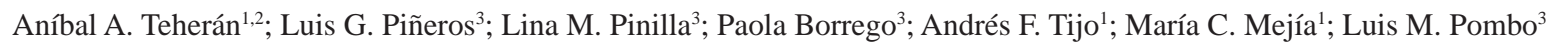

1 COMPLEXUS Research Group. Fundación Universitaria Juan N. Corpas. Cra. 111 \#157-61, Bogotá. Colombia

2 Emergency Medicine Resident of Universidad del Rosario.

3 GIFVTA Research Group. Fundación Universitaria Juan N. Corpas. Cra. 111 \#157-61, Bogotá. Colombia

Correspondencia: Luis M. Pombo. GIFVTA Research Group. Fundación Universitaria Juan N. Corpas. Cra. 111 \#157-61, Bogotá. Colombia.

E-mail: miguel.pombo@juanncorpas.edu.co

Como citar: Teherán AA, Piñeros LG, Pinilla LM, Borrego P, Tijo AF, Mejía MC, et al. Effectiveness of alternative therapies for the management of lumbar disc disease: a descriptive research Cuarzo 2016; 22 (1): 1-12.

Recibido: 20 de enero de 2016. Aceptado: 25 de abril de 2016. Publicado: 30 de junio de 2016.

Licencia creative commons (c)

\begin{abstract}
BACKGROUND: Low back pain due to discopathy has become one of the most expensive and highest impact problems of global public health at present.

AIM: To evaluate the effectiveness of alternative therapies (AT) and related factors in lumbar disk disease (LDD).

METHODS: Information was collected by using a retrospective descriptive design from medical records of patients treated from January to December 2013 with LDD who were attended in a clinic specialized in AT. Sociodemographic and clinical variables included clinical diagnostic time, Visual Analog Scale at admission (V.A.S.) and post-treatment pain (0-100 points) were identified. General and specific influence of the AT was measured.
\end{abstract}

RESULTS: 453 medical records were identified, at admission V.A.S. was 8.2 (CI95\%, 7,9 to 8,3) and showed pain relief (scale 0-100) of 54,5 points (CI95\%, 52.2 to 56.8). In overall, 13 types of ATs were implemented with LDD patients. The median of pain relief (p25-p75) in the general population was 60 (40-70); 8 of 13 interventions provided an estimated median of pain relief lower than the one evidenced in the general population .

CONCLUSION: The AT treatment in our study showed a reduction in pain of 50-60 points and an absolute reduction of 35 points after two months of treatment, which remained over 6 or more months of follow-up. Our results suggest that the use of AT has significant effect on chronic pain in patients with LDD with no response to conventional treatment.

KEYWORDS: Low back pain, lumbar spinal discopathy, alternative therapies. 


\section{Resumen}

INTRODUCCIÓN. El dolor lumbar debido a la discopatía se ha convertido en uno de los problemas más caros y de mayor impacto de la salud pública mundial en la actualidad.

OBJETIVO: Evaluar la eficacia de las terapias alternativas (TA) y los factores relacionados en la enfermedad del disco lumbar (EDL).

METODOLOGÍA: La información fue recolectada utilizando un diseño descriptivo retrospectivo de los registros médicos de los pacientes tratados de enero a diciembre de 2013 con EDL que asistieron a una clínica especializada en TA. Las variables sociodemográficas y clínicas incluyeron tiempo de diagnóstico clínico, escala visual analóga al ingreso (V.A.S.) y dolor post-tratamiento (0-100 puntos). Se midió la influencia general y específica de las TA.

RESULTADOS: Se identificaron 453 expedientes médicos, al ingreso el V.A.S. fue de 8,2 (IC95\%, 7,9 a 8,3) y mostró alivio del dolor (escala 0-100) de 54,5 puntos (IC95\%, 52,2 a 56,8). En general, 13 tipos de TA se implementaron con pacientes EDL. La mediana del alivio del dolor en la población general fue de 60 puntos (40-70) y 8 de 13 intervenciones proporcionaron una mediana estimada de alivio del dolor menor que la evidenciada en la población general.

CONCLUSIÓN: En nuestro estudio el tratamiento con TA mostró una reducción en el dolor de 50-60 puntos y una reducción absoluta de 35 puntos después de dos meses de tratamiento, que se mantuvo durante 6 o más meses de seguimiento. Nuestros resultados sugieren que el uso de TA tienen un efecto significativo sobre el dolor crónico en pacientes con EDL sin respuesta al tratamiento convencional.

PALABRAS CLAVE: Dolor lumbar, discopatía, terapias alternativas.

\section{Introduction}

Low back pain due to discopathy has become one of the most expensive and highest impact problems of global public health at present; at least $80 \%$ of the world's general population experienced low back pain at some point in their lives (1). In the United States, approximately $75 \%$ of the population has suffered from back pain and $25 \%$ of these cases lead to medical leaves, which causes an annual loss of 1,400 working days per 1,000 workers (2). In Colombia, low back pain is one of the most recurrent reasons for medical consultation and is the most frequent cause of activity limitation in people over 45 years old (3). The relevance as a public health problem of this disease lies in the frequency of progression leading to chronicity, the medical leaves generated, impacting economically active population and high healthcare costs that exceed those of many illnesses, including coronary heart disease.

Lumbar Disk Disease (LDD) commonly leads patients to a quality of life deterioration and compromises labor, economic, social, family and emotional spheres. Among the pathophysiological factors involved, pain is the main determinant of a partial or permanent labor-related disability. In a comparative analysis, Radziszewki reported a significant reduction of the capacity for professional work in patients with intervertebral disc disease in the lumbar spine (2). Consequently, pain control is one of the most significant therapeutic aspects and constitutes, together with functionality parameters, the most important criteria when determining treatment effectiveness (4).

Some studies oriented toward establishing the action of the alternative therapies (AT), suggest reduction in pain and symptom intensity, as well as an earlier return to work activities in patients with LDD. However, methodological limitations such as lack of uniformity in the definition of the disease, difficulties when monitoring patients, convenience samples, heterogeneity in population groups, and problems to discriminate the effects of specific treatments were identified (4). It is necessary to conduct a research to explore the effectiveness of alternative therapies in the treatment of patients with LDD, in order to provide evidence to support the use of these therapeutic methods, in patients with poor response to a conventional medical treatment. 


\section{Methodology}

\section{Study design and settings}

This was a descriptive research, performed with clinical registries in patients attended in UNIMED (Bogotá, Colombia). This care center provides outpatient medical consultation together with therapeutic procedures considered as alternative or complementary, including: pulsed magnetic fields, polarizing solutions (Glucoseinsulin-potassium solutions), ozone therapy, homeopathy, acupuncture, neural therapy, hydrotherapy, LASER and medicinal plant pharmacology. Research was classified without risk, based on 008430/1993 resolution, confidentiality of patients was guaranteed and approved by the Research Committee of Juan N. Corpas University.

\section{Selection of participants}

Convenience sampling was performed, based on a database containing relevant medical records of the period from January to December 2013. The following diagnoses potentially associated with LDD were initially identified: lumbago/back pain, lumbar disc disorder, discopathy/lumbar radiculopathy, disc herniation and spondylopathies (See additional files). LDD diagnosis was established in all patients with defined diagnosis by a specialist in Neurosurgery, Orthopedics, as a result of complementary tests or diagnosis described in medical records. Separately, two researchers (TAF, TAA) reviewed the medical records and included patients who received 2 or more continuous sessions of some type of AT for the diagnosis of LDD; any uncertainty about the diagnosis was resolved by a third investigator (PLM). Patients who received only one medical inspection, were not treated or had secondary spinal cord injury to neoplasia were excluded (Figure S1, see supplementary files).

These data were stored on an Excel spreadsheet (Microsoft Office), containing sociodemographic variables, admission visual analog scale (V.A.S) score improvement at discharge (scale 0-100 points), diagnosis of LDD time (days), treatment time with AT (months), signs or symptoms at admission, disease history, specialists treatment, surgical intervention, pharmacological history (current or last 3 months), type of conventional treatment and sort of AT, including the number of sessions practiced (https://drive.google.com/drive/folders/0B0BzWSj_ng8CakRTZnVuZFNvakU ).

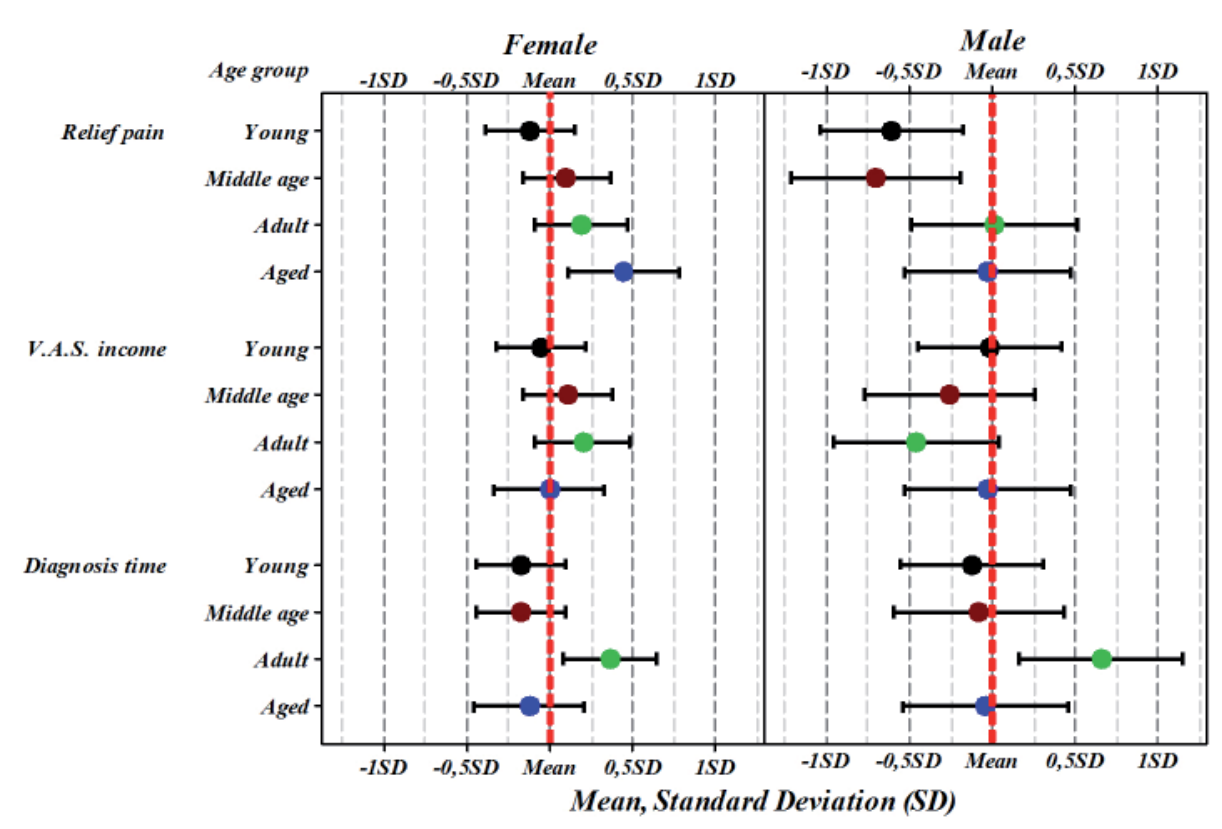

FIGURE 1. Clinical evolution time, pain score at admission and pain relief, standardized by age group and gender. Measurements of clinical evolution of pain, pain score at admission (V.A.S.) and pain relief (scale 0-100 points) were standardized. Independently, according to gender, standardized scores were compared for each measurement in each age subgroup, taking the standardized average (dotted red line) as reference. 
Patients were grouped into a first treatment phase, consisting of: 4 sessions for neural therapy, hydrotherapy, acupuncture, laser, vibratory therapy and electrostimulation or 6 treatment sessions for the rest of the AT.

\section{Outcome measures}

The outcome effectiveness of pain treatment was evaluated with a relief pain score (0-100 points), regarding sociodemographic and clinical features. It was estimated from the difference between pain score at admission minus pain during the last consultation (CI95\%) (posttreatment pain score ); to calculate the difference, it was necessary to convert the pain score at admission (V.A.S., 0-10 point) to a $0-100$ point score.

\section{Statistical analysis}

Statistical analysis was performed with the Minitab V-17 software; it initially performed a descriptive statistical analysis in order to express numerical and categorical variables; data were standardized, (x - mean/ standard deviation), to represent in the same figure, V.A.S., diagnosis time and relief point score.

An unpaired t-Student test was used to establish differences in V.A.S., diagnosis time and relief pain score related to admission clinical conditions; a secondary to type and frequency AT's variability (non-parametric analysis) Mann-Whitney $\mathrm{U}$ and Wilcoxon tests, were performed, with the purpose of establishing differences between treatment phases for every specific AT and base differences against median relief of pain in general population, respectively; two-tails $\mathrm{p}<0.05$ was established as significant.

The grade of pain relief was established with a onetail paired t-test, calculating the difference between posttreatment pain score (post-treat) and admission pain score (CI95\%), along all treatment, at 2, 3-4, 5-6 and more than 6 months of therapy, in order to assess significant changes from early stages of treatment with AT.

\section{Results}

806 medical records were identified in the database of patients assisted during 2013, out of these, $93.9 \%$ had a potential diagnosis of lumbar disc disease; $40 \%$ were excluded due to lack of continuity in the clinical follow-up (Figure S1).

\section{Overall characteristics}

Most of the 453 patients included were women (74.6\%) with a mean age of 57 years old and also most of them lived with a stable partner (66.9\%). Information on the socioeconomic status (SES) was identified in 37.6\%; 9 out of 10 patients belonged to a middle or low SES (CI 95\%, 90.3 to $97.9 \%$ ) (Table 1 ).

\section{Clinical conditions at admission and pain relief}

Information about clinical evolution time and V.A.S. was found in 417/453 (92.1\%) and 260/453 (57.4\%) of the medical records, respectively. On average, patients had 52,2 days of clinical evolution (CI95\%, 48,3 to 56,1), V.A.S. of 8.2 (CI95\%, 7,9 to 8,3) and showed pain relief (scale $0-100$ ) of 54,5 points (CI95\%, 52.2 to 56.8 ).

The average clinical evolution time, the V.A.S score and pain relief in women were $52 \pm 4.0$ days, $8.2 \pm 1.42$, $55.5 \pm 23.5$, respectively, and in men were $54 \pm 4.1,7.9 \pm$ 1.7 and $51.3 \pm 24.1$. Adult patients had longer evolution time (p: 0.005); without statistical differences, young female adults and female adults showed higher V.A.S at admission than young and senior women; young male adults and male adults showed lower V.A.S at admission than young men and senior men (Figure 1).

TABLE 1. Sociodemographic characteristics.

\begin{tabular}{lcc}
\multicolumn{1}{l}{ Baseline characteristics } & $\mathrm{n}:(\%)$ & $\mathrm{p}$ \\
Age, years & $56.9 \pm 12,7$ & NA \\
Gender & & \\
$\quad$ Male & $338 / 453(74,6)$ & $* * *$ \\
$\quad$ Female & $115 / 453(25,4)$ & \\
Marital status & & \\
$\quad$ Married/Common Law & $303 / 453(66,9)$ & $* * *$ \\
$\quad$ Single / Divorced / Widowed & $150 / 453(33,1)$ & \\
Socioeconomic status & \\
$\quad$ & & \\
$\quad$ High & & \\
$\quad$ Medium & $10 / 170(5,9)$ & $* * *$ \\
$\quad$ Low74/170 (50,6) & $86 / 170(43,5)$ & \\
\end{tabular}

Age $\pm \mathrm{SD}$, a: differences presents medium and low socioeconomic status. $* * * \mathrm{p}<0.001 . \mathrm{X}^{2}$ test was used to establish differences. 
The pain decreased while increasing the age group, especially in women, where statistical differences were evidenced when comparing the group of young people to senior adults (p: 0.010); in men, differences were found when comparing young or middle age groups to adult or senior groups (p: 0.010).

Among signs/symptoms, the most frequent were pain in lumbar/sacral/lower limb regions (98.2\%), followed by rest pain that increases with position changes (82.8\%) and sitting position (56.5\%). A previous surgical intervention related to disc disease was the most frequent treatment (16.6\%).

Most patients had received treatment by orthopedic specialists (47.7\%) and physical therapy (38.4\%) (Figure 2).

The clinical evolution time regarding signs/symptoms was higher in patients with cramps, previously treated by the Department of Orthopedics or with a surgical history of disc disease, but lower in those with allergies to opioids / NSAID ( $<$ <0.05); at admission, the V.A.S. was higher in those patients previously treated by Physical Therapy (p: $<0.05$ ); additionally, patients admitted with pain at rest/ postural changes, sitting or currently managed with anal- gesics (unspecified), had lower post-treatment scores (p: $<0.05$ ) (Table S1-S4).

\section{Modalities of alternative therapies employed.}

In overall, the following 13 types of ATs were implemented with LDD patients: general pulsating magnetic field of 100 Gauss, local magnetic field of 100 Gauss, overall magnetic field of 200 Gauss, Metabolic Treatment with magnetic field of 100 Gauss, Metabolic Treatment with 200 Gauss magnetic field, Neural Therapy, Acupuncture, Electroacupuncture, and Electrostimulation, Moxibustion, Local Ozone, Intramuscular Paravertebral Ozone, Hydrotherapy, Vibration Therapy and LASER.

\section{Effectiveness of Alternative Therapies (AT)}

The median of pain relief (p25-p75) in the general population was 60 (40-70), with an interval from 50 to 60 points; 8 of 13 interventions provided an estimated median of pain relief lower than the one evidenced in the general population (Figure 3).

Table 2 shows pain relief among different types of AT, according to two treatment phases. When compared with the median pain relief in the general population, during

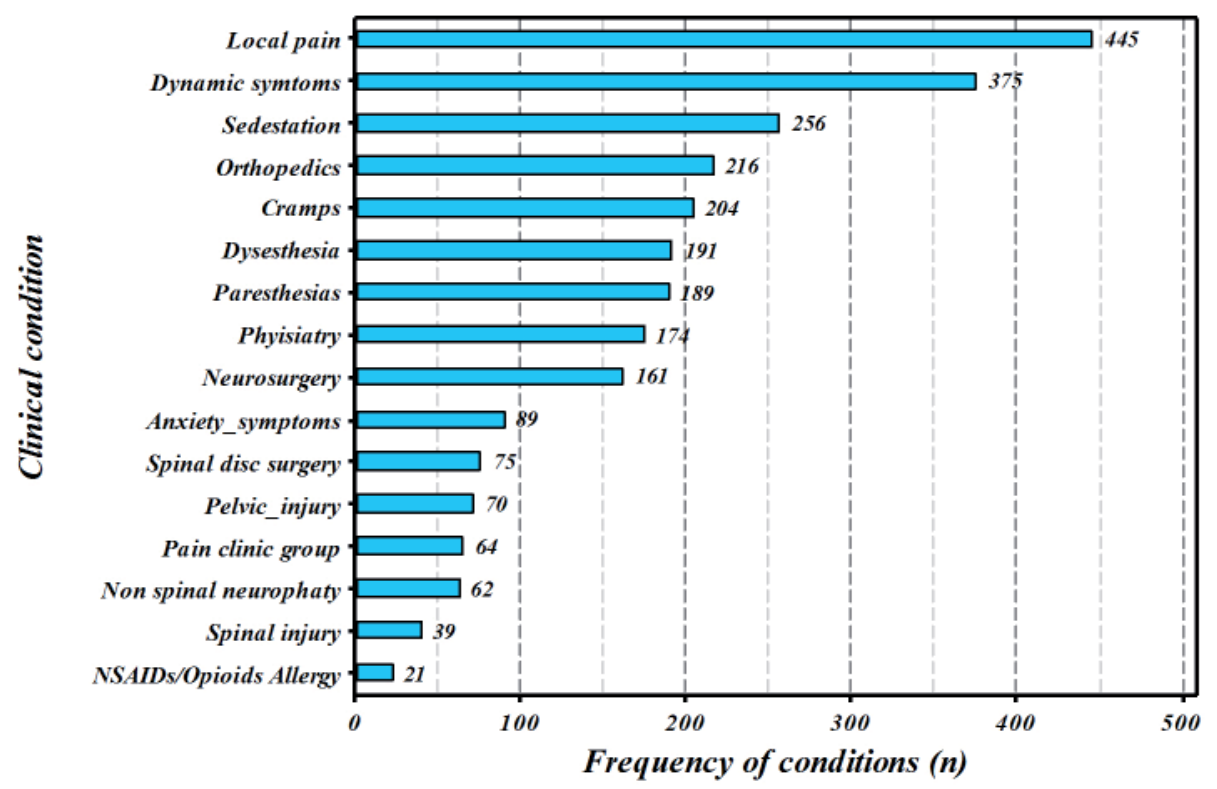

FIGURE 2. Frequency of signs, symptoms and medical history. Local pain: Lumbar, sacral or lower limbs, Dynamic symptoms: Pain at rest or in motion exchange. Orthopedics, Neurosurgery, Physiatry, Pain Clinic Group: History of previous treatment. 
TABLE 2. Median relief pain comparison between phases of treatment and the general population.

\begin{tabular}{|c|c|c|c|c|c|}
\hline \multirow[t]{2}{*}{ Therapy } & \multicolumn{2}{|c|}{ Treatment phases } & \multirow{2}{*}{$\begin{array}{c}\text { First Vs } \\
\text { Additional } \\
\text { p-value }\end{array}$} & \multirow{2}{*}{$\begin{array}{c}\text { General Vs } \\
\text { First } \\
\text { p-value }\end{array}$} & \multirow{2}{*}{$\begin{array}{c}\text { General Vs } \\
\text { Additional } \\
\text { p-value }\end{array}$} \\
\hline & First & Additional & & & \\
\hline MF-100 & $50(37,5)$ & $50(40,0)$ & 0,280 & 0,006 & 0,002 \\
\hline MF-200 & $60(40,0)$ & $60(30,0)$ & 0,067 & 0,585 & 0,001 \\
\hline LF $50(27,5)$ & $60(35,0)$ & 0,836 & 0,142 & 0,584 & \\
\hline MMF-200 & $60(30,0)$ & $50(50,0)$ & 0,264 & 0,296 & 0,045 \\
\hline Neural & $60(40,0)$ & $60(30,0)$ & 0,185 & 0,462 & 0,001 \\
\hline Acupuncture & $50(50,0)$ & $55(35,0)$ & 0,497 & 0,065 & 0,451 \\
\hline Ozone & $60(30,0)$ & $60(27,5)$ & 0,322 & 0,003 & 0,377 \\
\hline Moxibustion & $50(55,0)$ & $40(45,0)$ & 0,906 & 0,343 & 0,178 \\
\hline Electrostimulation & $60(40,0)$ & $45(40,0)$ & 0,360 & 0,889 & 0,465 \\
\hline
\end{tabular}

Median, interquartile range (IQR). MF-100: magnetic field 100, MF-200: magnetic field 200.MMF: metabolic magnetic field. The differences between phases was established with U-Mann Whitney test and between general outcome and the first phase or additional phases (plus) was established with a Wilcoxon test, P-values were calculated with a two-tail hypothesis.

TABLE 3. Pain relief score at different times of the treatment with alternative therapies.

\begin{tabular}{lccccc} 
Treatment & $\mathrm{n}$ & \multicolumn{2}{c}{$\begin{array}{c}\text { Score pain (mean } \pm \text { SD) } \\
\text { Admission }\end{array}$} & Difference $(\mathrm{Cl95} \%)$ & \\
& & Post-treat & Advalue & \\
Total & 260 & $45,5 \pm 24$ & $81,5 \pm 15,2$ & $-35,9(-38,9,-33)$ & $<0,001$ \\
2 months & 5 & $54 \pm 33,6$ & $82 \pm 10,9$ & $-28(-54,5,-1,5)$ & 0,044 \\
$3-4$ months & 11 & $48,2 \pm 19,4$ & $79,1 \pm 14,5$ & $-30,9(-43,9,-17,9)$ & $<0,001$ \\
$5-6$ months & 17 & $57,1 \pm 31,2$ & $83,5 \pm 37,7$ & $-26,5(-42,2,-10,8)$ & 0,005 \\
$>6$ months & 227 & $44,3 \pm 23,3$ & $81,4 \pm 15,4$ & $-37,1(-40,3,-33,9)$ & $<0,001$ \\
\hline
\end{tabular}

Score pain: 0-100 points. This analysis was done only in patients with both, admission and current score of pain information.

the first phase of treatment, 5 types of therapeutic interventions were less effective in relieving pain $(\mathrm{p}<0.05)$; during additional phases, 4 interventions were less effective $(p<0.05)$. Among these interventions that showed low effectiveness, the estimated median pain relief remained at least in 50 points (data not shown).

In general, an absolute decrease in pain of 35 points was observed, in comparison to the pain measured in the admission; this decrease in pain was at least 25 points and as high as 37 points and was identified from the first two months of treatment (Table 3, Figure 4).

\section{Discussion}

In this research we were able to characterize patients treated by lumbar disc disease, with poor or no response to conventional treatment, then treated with AT; the effectiveness of these therapies was evaluated and a substantial improvement was found, but not related to clinical variables evidenced at admission.

All patients included in the study received a conventional treatment, 7 out of 10 received treatment for a medical-surgical specialty with skills and resources to treat 


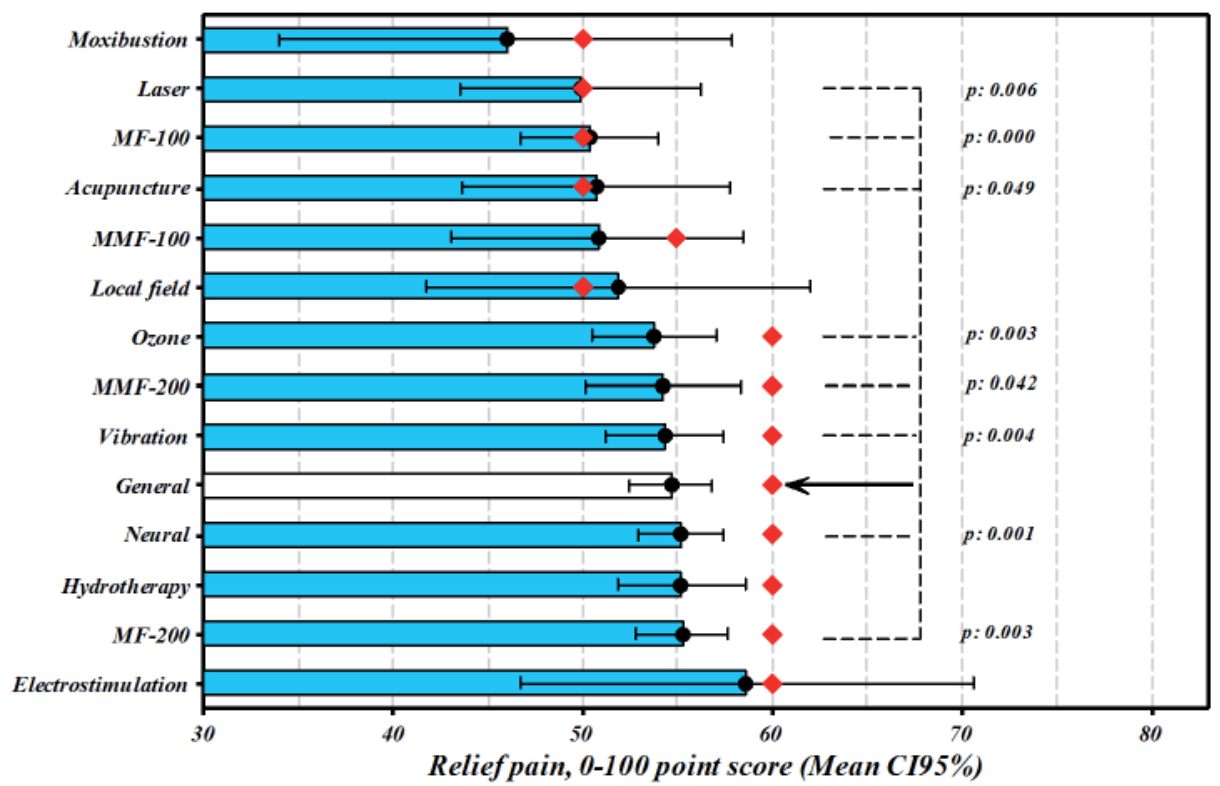

FIGURE 3. Comparison between pain relief and specific alternative therapies in the general population. MF: magnetic field; MMF: metabolic magnetic field; Black Circle: means; Red Diamonds: medians. A difference was established with a two-tail Wilcoxon test.

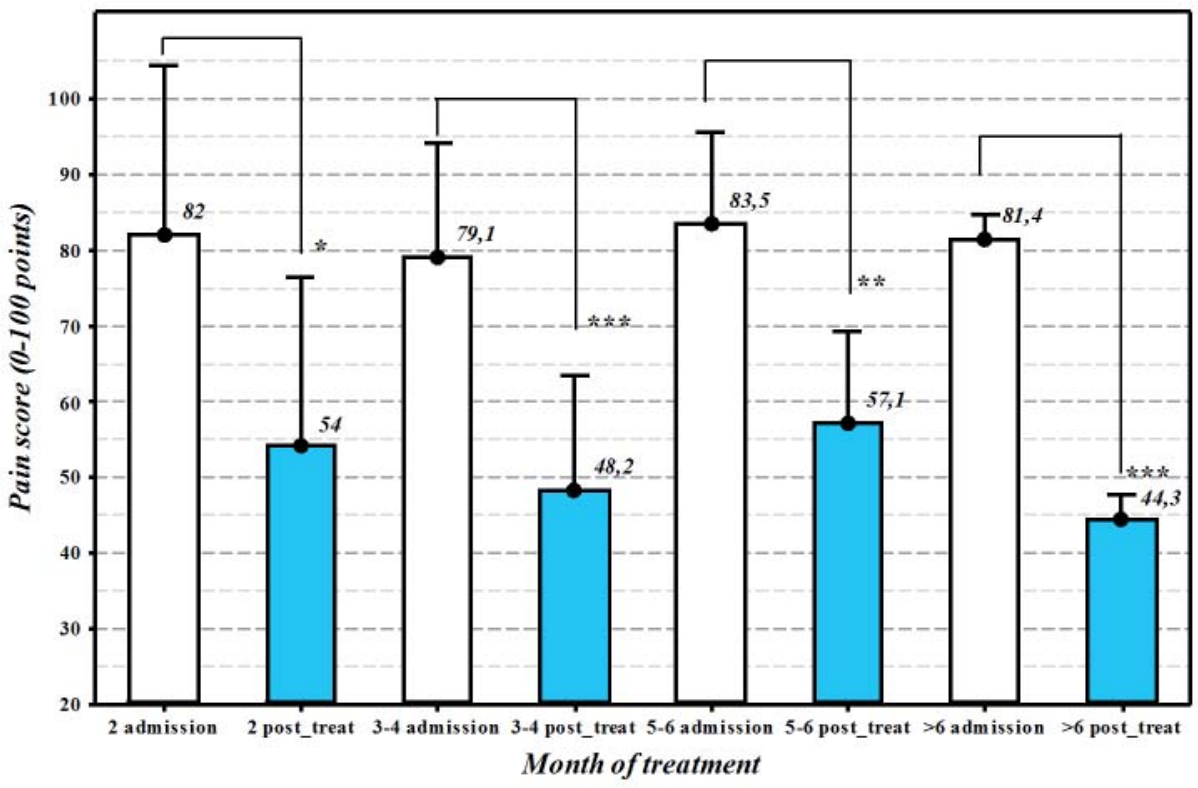

FIGURE 4. Mean pain score at admission and post-treatment at different times of pain treatment. Admission: pain at the admission, post-treatment: pain at the moment of review of the medical record. The difference between post-treatment - admission was established with a one-tail, paired t-test, with Bonferroni's adjusted. * $\mathrm{p}<0.05,{ }^{* *} \mathrm{p}<0.01,{ }^{* * *} \mathrm{p}<0.001$. 
the pain (Orthopedics, Physical Medicine, Neurosurgery and Pain Clinic), they had 7 or more weeks of pain evolution and the V.A.S score at admission was high $(>8)$; These features showed that despite having received the usual treatment, the patients were suffering chronic low back pain, with high scores on the intensity assessment.

In the case of chronic skeletal muscle pain and chronic low back pain, the minimal reduction in pain score (scale $0-100$ ), considered as significant was 20 points (1). The AT treatment in our study showed a reduction in pain of 50-60 points and an absolute reduction of 35 points after two months of treatment, which remained over 6 or more months of follow-up. Our results suggest that the use of AT has significant effect on chronic pain in patients with lumbar disc disease with no response to conventional treatment.

Comparison of combined treatment with respect to therapeutics used in an individually way can become difficult due to the small number of available studies, methodological limitations, heterogeneity in the inclusion criteria, follow-up periods and outcome measures. However, most research is oriented towards effectiveness of acupuncture in the treatment of nonspecific chronic pain in low back. The results of two meta-analysis showed a significant analgesic effect immediately after therapy (2, 3 ), but only one of them reported a sustained long term reduction of pain (3). Our results showed that pain relief related to acupuncture and other types of AT was sustained in early stages as in additional treatments.

Therapies using different forms of massage have shown to be effective in inducing analgesia right after therapy in patients with acute and subacute low back pain, but not in patients with chronic pain (2); This research showed a significant reduction, in the long term, in the intensity of chronic pain with the use of a vibrating massage.

Pulsed low-frequency magnetic fields produced 30\% higher improvement in pain relief associated to FBSS (failed-back surgery syndrome), after 45 days of continuous treatment, with exposure of 30 minutes, twice a day (4). In our study, the reduction of chronic low back pain was presented with the use of magnetic fields at 100 and 200 Gauss of intensity, used for periods of one to two continuous hours, and once or twice a week during the follow-up time.
In medical evaluations made during 6 months, the application of ozone-oxygen mixtures in paraspinal muscles induced pain remission in $61 \%$ of patients with lumbar disc herniation who did not respond to a conservative treatment (5). Coinciding with these findings, this study found a significant reduction in pain intensity associated to long-term application of ozone.

In relation to conventional procedures, the epidural injection effectiveness has been assessed in studies reporting an improvement higher than 50\% and 74 to $84 \%$ of patients treated with local anesthetic and local anesthetic plus betamethasone respectively, during the monitoring of 12 months (6). In addition, a higher than $40 \%$ improvement was reported in $55.5 \%$ and $63.2 \%$ of patients who were injected with Mepivacaine and Mepivacaine plus methylprednisolone respectively, during a 3-month follow-up (7). Positive results were also obtained when evaluating long-term injections of Lidocaine - Triamcinolone, Triamcinolone - Bupivacaine, Bupivacaine Methylprednisolone and epidural steroids (8-11).

Our results showed that patients treated with NSAIDs, steroids, muscle relaxants and other conventional handlings, showed improvement scores of about $50 \%$, but no differences with those not treated with these therapeutic strategies.

Among the methodological limitations, we shall mention the observational design and the use of a retrospective database containing the variables studied; both factors may influence the effectiveness of the AT, since we did not evaluate the effect of the combination and the specific number of AT; on the other hand, between the monitoring time intervals established, there was uniformity of time per patient and this may affect the accuracy of the results.

The results obtained suggest a significant effectiveness of AT in reducing pain in patients with lumbar disc disease, especially in those previously treated, without favorable response to conventional therapy. Pain improvement is evident from the second month of treatment and pain reduction is two to three times as established as significant in the studies of effectiveness in the treatment of musculoskeletal and chronic low back pain.

The effectiveness of AT to decrease pain depending on the possible therapeutic combinations and the number of sessions per therapy should be explored, in order to ob- 
tain the minimum dose and more efficient combination to reduce pain. In addition, it is necessary to carry out prospective studies exploring the recovery of physical activity, quality of life and other indicators of functional improvement, as well as possible structural changes in diagnostic imaging.

LIST OF ABBREVIATIONS: LDD: Lumbar Disc Disease, AT: Alternative therapy, V.A.S: Visual Analog Scale, SES: Socioeconomic status, NSAID: Non-steroidal antinflammatory drugs

ACKNOWLEDGEMENT: The authors would like to thank the Academic Vice-President's Office of Fundación Universitaria Juan N. Corpas for its financial support of this research. And the fifth- year medical students Laura Caballero and Inge Bulla, who worked on the phases of the proposed research and data collection respectively.

CONFLICT OF INTEREST: The authors declare that they do not have a conflict of interest.

FUNDING SOURCE: The database was provided by UNIMED

AUTHORSHIP: All authors made substantial contributions to the conception and design of the study, acquisition of data, analysis and interpretation of data, drafting the article and final approval of the version to be submitted.

\section{References}

1. Benyamin RM, Manchikanti L, Parr AT, Diwan S, Singh V, Falco FJ, et al. The effectiveness of lumbar interlaminar epidural injections in managing chronic low back and lower extremity pain. Pain Physician. 2012 Jul-Aug;15(4):E363-404

2. Furlan AD, Yazdi F, Tsertsvadze A, Gross A, Van Tulder M, Santaguida L, et al. Complementary and Alternative Therapies for
Back Pain II. Rockville (MD): Agency for Healthcare Research and Quality (US); 2010. Available from: http://www.ncbi.nlm. nih.gov/books/NBK56304/

3. Manheimer E, White A, Berman B, Forys K, Ernst E. MetaAnalysis: Acupuncture for Low Back Pain. Ann Intern Med. 2005; Abr 19;142(8):651-63

4. Harper WL, Schmidt WK, Kubat NJ, Isenberg RA. An open-label pilot study of pulsed electromagnetic field therapy in the treatment of failed back surgery syndrome pain. Int Med Case Rep J. 2014 Dec 31;8:13-22. doi:10.2147/IMCRJ.S73068. eCollection 2015.

5. Paoloni M, Di Sante L, Cacchio A, Apuzzo D, Marotta S, Razzano $\mathrm{M}$, et al. Intramuscular oxygen-ozone therapy in the treatment of acute back pain with lumbar disc herniation: a multicenter, randomized, double-blind, clinical trial of active and simulated lumbar paravertebral injection. Spine (Phila Pa 1976). 2009 Jun 1;34(13):1337-44. doi: 10.1097/BRS.0b013e3181a3c18d.

6. Manchikanti L, Singh V, Falco FJE, Cash KA, Pampati V. Evaluation of the effectiveness of lumbar interlaminar epidural injections in managing chronic pain of lumbar disc herniation or radiculitis: A randomized, double-blind, controlled trial. Pain Physician 2010 Jul- Aug; 13(4):343-355.

7. Fukusaki M, Kobayashi I, Hara T, Sumikawa K. Symptoms of spinal stenosis do not improve after epidural steroid injection. Clin J Pain. 1998 Jun; 14 (2):148-151.

8. Lee JH, An JH, Lee SH. Comparison of the effectiveness of interlaminar and bilateral transforaminal epidural steroid injections in treatment of patients with lumbosacral disc herniation and spinal stenosis. Clin J Pain 2009 Mar - Apr; 25 (3):206-210. doi: 10.1097/AJP.0b013e3181878f9e.

9. Koc Z, Ozcakir S, Sivrioglu K, Gurbet A, Kucukoglu S. Effectiveness of physical therapy and epidural steroid injections in lumbar spinal stenosis. Spine (Phila Pa 1976) 2009 May 1; 34 (10): 985-9. doi: 10.1097/BRS.0b013e31819c0a6b

10. Wilson-MacDonald J, Burt G, Griffin D, Glynn C. Epidural steroid injection for nerve root compression: A randomized, controlled trial. J Bone Joint Surg Br. 2005 Mar; 87 (3):352-355.

11. Kapural L, Mekhail N, Bena J, McLain R, Tetzlaff J, Kapural M, et al. Value of the magnetic resonance imaging in patients with painful lumbar spinal stenosis (LSS) undergoing lumbar epidural steroid injections. Clin J Pain 2007 Sept; 23 (7):571-5. 


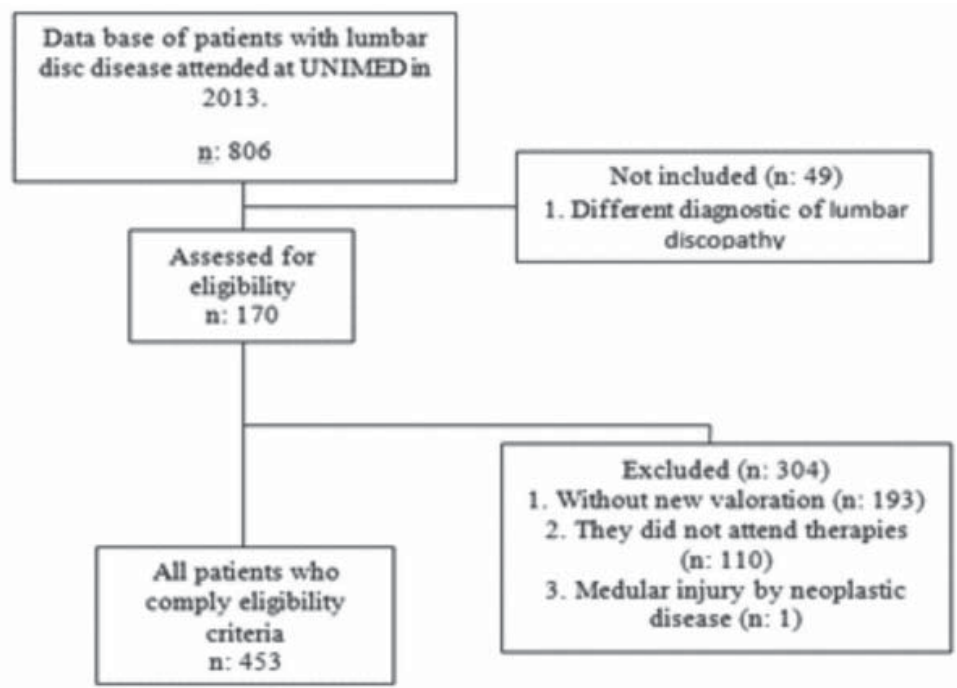

FIGURE S1. Selection algorithm of patients diagnosed with lumbar discopathy treated at UNIMED with alternative therapies in 2013.

TABLE S1. Clinical conditions related to the time evolution of signs / symptoms (days).

\begin{tabular}{|c|c|c|c|}
\hline \multirow[t]{2}{*}{ Condition at admission } & Yes & No & \multirow[t]{2}{*}{$p$-value } \\
\hline & $n(\bar{X} \pm S D)$ & $n(\bar{X} \pm S D)$ & \\
\hline \multicolumn{4}{|l|}{ Signs/Symptoms } \\
\hline Local pain & $409(52,4 \pm 40,6)$ & $8(44,9 \pm 32,8)$ & 0,545 \\
\hline Dynamic symptoms & $351(52,4 \pm 41,9)$ & $66(51,4 \pm 31,5)$ & 0,825 \\
\hline Sedestation & $236(53,3 \pm 46,8)$ & $181(50,8 \pm 30,3)$ & 0,500 \\
\hline Dysesthesia & $184(56,5 \pm 50,0)$ & $233(48,8 \pm 30,5)$ & 0,067 \\
\hline \multicolumn{4}{|l|}{ Background } \\
\hline Pelvic trauma & $68(48,6 \pm 30,9)$ & $349(52,9 \pm 42,1)$ & 0,327 \\
\hline Spinal injury & $39(47,5 \pm 32,0)$ & $378(52,7 \pm 41,2)$ & 0,384 \\
\hline Surgical - Discopathy & $71(62,7 \pm 35,4)$ & $346(50,1 \pm 41,1)$ & 0,009 \\
\hline Neurosurgery & $155(50,9 \pm 32,4)$ & $262(50,3 \pm 44,6)$ & 0,583 \\
\hline Physiatry & $169(56,6 \pm 47,6)$ & $248(49,3 \pm 34,5)$ & 0,086 \\
\hline Pain management clinic & $62(53,0 \pm 28,6)$ & $355(52,1 \pm 42,2)$ & 0,843 \\
\hline
\end{tabular}

$\overline{\mathrm{X}}$ : mean: SD standard deviation, V.A.S.: Visual Analog Scale. Local pain: lumbar, sacral or lower limbs, Dynamic Symptoms: pain at rest or in motion changes. Orthopedics / Neurosurgery / Physical Medicine / Pain Management Clinic: History of previous treatment. 
TABLE S2. Clinical conditions related to pain score at admission (V.A.S.)

\begin{tabular}{lccc} 
Condition at admission & Yes & No & p- value \\
\cline { 2 - 4 } & $\mathrm{n}(\overline{\mathrm{X}} \pm \mathrm{SD})$ & $\mathrm{n}(\overline{\mathrm{X}} \pm \mathrm{SD})$ & \\
Signs/Symptoms & & & \\
& & & \\
Local pain & $255(8,16 \pm 1,51)$ & $36(7,90 \pm 2,07)$ & 0,463 \\
Dynamic symptoms & $224(8,17 \pm 1,49)$ & $113(8,17 \pm 1,32)$ & 0,828 \\
Sedestation & $147(8,13 \pm 1,65)$ & $132(8,05 \pm 1,59)$ & 0,312 \\
Cramps & $128(8,24 \pm 1,43)$ & $137(8,01 \pm 1,49)$ & 0,131 \\
Paresthesia & $123(8,29 \pm 1,54)$ & $142(8,19 \pm 1,42)$ & 0,597 \\
Dysesthesia & $118(8,09 \pm 1,63)$ & & \\
Background & & & 0,146 \\
Pelvic trauma & & $216(8,09 \pm 1,54)$ & 0,183 \\
Spinal injury & $44(8,43 \pm 1,39)$ & $235(8,11 \pm 1,55)$ & 0,602 \\
Surgical - Discopathy & $25(8,44 \pm 1,08)$ & $221(8,17 \pm 1,51)$ & 0,051 \\
Peripheral neuropathy & $39(8,03 \pm 1,56)$ & $224(8,22 \pm 1,52)$ & 0,621 \\
Psychiatric & $36(7,69 \pm 1,43)$ & $216(8,17 \pm 1,53)$ & 0,943 \\
Allergy Opioid/NSAID & $44(8,05 \pm 1,46)$ & $251(8,15 \pm 1,52)$ & 0,285 \\
Orthopedics & $9(8,11 \pm 1,45)$ & $124(8,04 \pm 1,57)$ & 0,301 \\
Neurosurgery & $136(8,24 \pm 1,46)$ & $166(8,22 \pm 1,42)$ & 0,016 \\
Physiatry & $94(8,01 \pm 1,67)$ & $149(7,96 \pm 1,66)$ & 0,473 \\
Pain management clinic & $111(8,40 \pm 1,26)$ & $218(8,12 \pm 1,55)$ & \\
\hline X: & $42(8,29 \pm 1,33)$ & & \\
\hline
\end{tabular}

$\bar{X}$ : mean: SD standard deviation, V.A.S.: Visual Analog Scale. Local pain: lumbar, sacral or lower limbs, Dynamic Symptoms: pain at rest or in motion changes. Orthopedics / Neurosurgery / Physical Medicine / Pain Management Clinic: History of previous treatment.

TABLE S3. Clinical conditions related to pain improvement (scale 0-100).

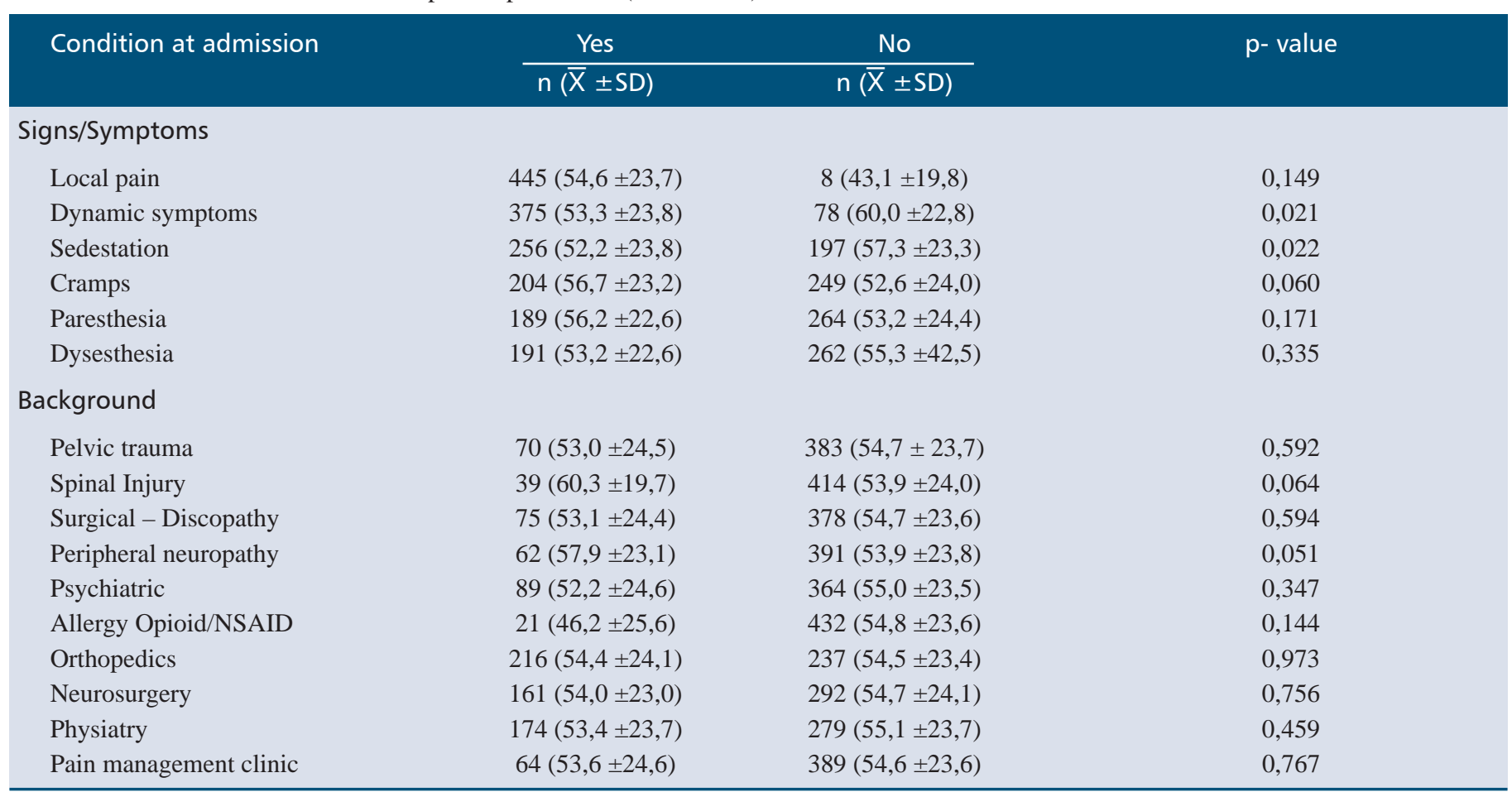

$\bar{X}$ : mean: SD standard deviation, V.A.S.: Visual Analog Scale. Local pain: lumbar, sacral or lower limbs, dynamic Symptoms: pain at rest or in motion changes. Orthopedics / Neurosurgery / Physical Medicine / Pain Management Clinic: History of previous treatment. 
TABLE S4. Improvement according to clinical conditions.

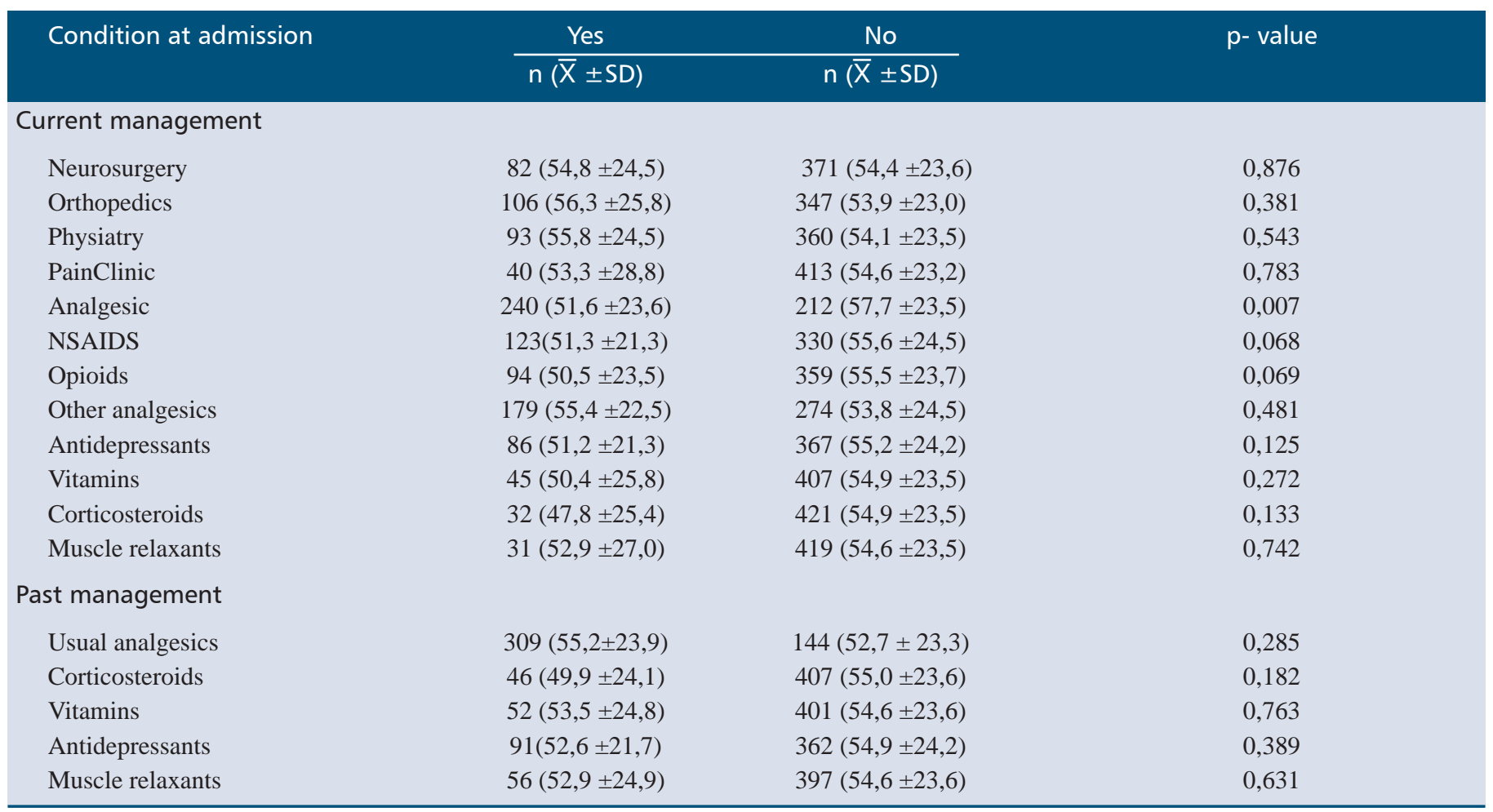

$\overline{\mathrm{X}}$ : mean, SD standard deviation, V.A.S.: Visual Analog Scale. Past management: last three months. 